\title{
Unscheduled Return Visits and Leaving the Chest Pain Unit Against Medical Advice
}

\author{
Yaser Jenab ${ }^{1, *}$; Shima Haghani ${ }^{2}$; Arash Jalali ${ }^{2}$; Farzad Darabi $^{2}$ \\ ${ }^{1}$ General Cardiology Department, Tehran University of Medical Sciences, Tehran, IR Iran \\ ${ }^{2}$ Clinical Research Department, Tehran University of Medical Sciences, Tehran, IR Iran \\ ${ }^{*}$ Corresponding Author: Yaser Jenab, General Cardiology Department, Tehran University of Medical Sciences, Tehran, IR Iran. Tel: +98-2188029256, Fax: +98-2188029256, \\ E-mail: jenab@razi.tums.ac.ir
}

Received: February 25, 2014; Revised: September 18, 2014; Accepted: October 6, 2014

\begin{abstract}
Background: Rate of Unscheduled Return Visits (URVs) to the Emergency Department has been considered as a key indicator for evaluating the quality of the Emergency Department care for decades. A higher rate of URVs can have a negative impact on the quality of health care. Investigations of the reasons for these returns have indicated that many of these visits can be preventable.

Objectives: Given that there are no clear findings about the frequency and reasons for 72 hours URVs to the Chest Pain Unit (CPU), in the present study, we investigated the causes of 72 hours URVs to our CPU in order to find out the inadequacies, and propose preventive strategies.

Patients and Methods: This research was a single-center retrospective case control study in the setting of CPU of Tehran Heart Center (a 460-bed, tertiary-care teaching hospital), Tehran, Iran. The medical records of the patients who were presented to our CPU with the chief complaint of chest pain between December $28^{\text {th }}, 2010$ and February $28^{\text {th }}, 2011$ were reviewed. Of the 6247 eligible patients, forty-nine URVs that fulfilled our criteria were identified. The control group consisted of 196 patients who did not return to the Emergency Department during our study period.

Results: Patient-related factors accounted for most 72 hours URVs (49\%). Multivariable analysis revealed that in our CPU, leaving Against medical advice was the most important predictor for 72 hours URVs (Pvalue $<0.001$ ). Additionally, male sex, history of hypertension, firstvisit disposition to observation unit and age were the other factors associated with URVs.

Conclusions: Considering that the most frequent reason for our URVs was patient-related factors, where all cases had left the CPU Against Medical Advice (AMA) during their first attendance, we recommend that further appropriate strategies be devised to prevent leaving against medical advice.
\end{abstract}

Keywords: Chest Pain; Against Medical Advice; Return Visits

\section{Background}

Rate of Unscheduled Return Visits (URVs) to the Emergency Department has been considered as a key indicator for evaluating the quality of the Emergency Department care for decades (1). Unscheduled Return Visits are defined as return of a patient to the Emergency Department with the same chief complaint, which has not improved or has worsened within 72 hours of discharge (2). Based on previous studies, patients with certain chief complaints such as chest pain and dyspnea are likely to return to the Emergency Department within 72 hours of discharge $(1,3,4)$. Acute chest pain is one of the most common complaints at the Emergency Department. The need to confirm diagnosis and provide rapid and correct management of these patients has brought about the concept of the Chest Pain Unit (CPU) (5). Although excluding the presence of coronary disease for any CPU is critical, in low-risk patients complaining of chest pain, the probability of the presence of a cardiac origin is less than $7 \%(6,7)$. Accordingly, more than $90 \%$ of chest pains in low-risk patients have a non-cardiac etiology $(7,8)$. Failure to differentiate between cardiac and noncardiac origins of chest pain in the CPU can have severe consequences. When the chest pain returns, it is natural for a patient to seek further medical attention and these patients may or may not have been given instructions about recurrent pains during their first hospital admission $(7,9)$. As a result, investigation on whether or not the patient has received inappropriate treatment or been discharged without effective treatment is of vital importance.

Rates of URVs less than 1\% are deemed acceptable, yet this is far from constituting a universally accepted standard $(2,10,11)$. Hence, a rate of URVs more than a certain level reflects the malfunction of the Emergency Depart- 
ment $(2,12,13)$. Despite the fact that URVs should not be spontaneously regarded as a poor performance of health care service, there are multiple associated factors which should be investigated.

Previous studies on 72 hours URVs have demonstrated that a significant proportion of these visits are preventable. There have been only a few recent studies about factors associated with 72 hours returns. To our knowledge, all of these studies were conducted at general hospitals. In addition, to date, no study has addressed the reasons for URVs to a CPU.

\section{Objectives}

In the present study, we investigated the causes of 72 hours URVs to our CPU with a view to find inadequacies and to propose preventive strategies.

\section{Patients and Methods}

This single-center, retrospective, case-control study was performed in the setting of the CPU of Tehran Heart Center (a 460-bed, tertiary-care teaching hospital), Tehran, Iran. The medical records of the patients who were presented to the CPU with a chief complaint of chest pain between December $28^{\text {th }}, 2010$ and February $28^{\text {th }}, 2011$ were collected. The medical records of the patients with first-time CPU attendance as well as those of the patients with 72 hours URVs with the same chief complaint were studied. Of the 6247 eligible patients who had referred to the Emergency Department with the chief complaint of chest pain during the study period, forty-nine URVs with chief complaint of chest pain during both visits, who were resident of Tehran, with complete variable data that fulfilled our criteria, were identified. The control group consisted of 196 residents of Tehran, who did not return to the Emergency Department during our study period. The number of the patients in the control group was four times greater than the case group. The patients' demographic data, presenting complaints, vital signs, past medical history, drug abuse, presenting electrocardiography (ECG), first and second-visit disposition, and causes of revisits were recorded. Medical records of the first and second visits were evaluated by two cardiologists, whose consensus determined reasons for the returns. Reasons for return visits were classified to three groups of illness-related, patient-related and doctor-related. Illness-related returns were defined as the exacerbation or absence of improvement in the patients' symptoms or the occurrence of treatment side-effects. Doctor-related returns were defined as situations in which the doctor was primarily responsible for the patient's return visits by misdiagnosis or incorrect treatment. Patient-related returns were defined as situations in which the patient left the CPU Against Medical Advice (AMA). An abnormal ECG was defined as any non-sinus rhythm, ST-segment deviation ( $\geq 0.5 \mathrm{~mm}$ ), T-wave inversion ( $\geq 1 \mathrm{~mm}$ ), abnormal axis deviation and bundle branch block.

\subsection{Statistical Analysis}

Categorical variables were presented by frequencies and percentages and were compared between case and control groups using chi-square or Fisher's exact test. Continuous variables were expressed as mean \pm Standard Deviation (SD) and were compared between cases and controls using student's t or Mann-Whitney test. To determine multiple predictors of 72 hours URVs, backward Firth's bias reduced logistic regression approach with penalized profile likelihood for parameter estimates was used (14). This method was used because of a separate problem in ordinary logistic regression. Covariate effects on 72 hours URV were reported as odd ratios (OR) with 95\% confidence intervals (CIs). Package "logistf" from R software was used for the analysis (15).

\section{Results}

The demographic and clinical characteristics of the patients are depicted in Table 1 . The mean age was 51.86 \pm 17.25 years for the total population, ranging between 17 and 95 years. The patients in the case group were more likely to be male ( $69.4 \%$ vs. $45.4 \%$; P value $=0.003$ ) There was a significant difference between the case and control groups regarding the presence of dyspnea, which was the most frequently associated symptom ( $\mathrm{P}$ value $=0.010$ ). A significant difference was observed in the history of hypertension, dyslipidemia, diabetes and current cigarette smoking between the two groups. Seventy patients in the control group and 20 patients in the case group had abnormal ECGs at presentation (35.7\% vs. 40.8\%). High-Sensitivity Cardiac Troponin $\mathrm{T}$ test (hs-cTnT) was checked at presentation, which showed a significantly higher median value in the case group when compared to the control group (8.09 ng/L vs. $3.65 \mathrm{ng} / \mathrm{L}$; P value $=0.002$ ).

Patient-related factors accounted for most 72 hours URVs (49\%). All patient-related returns involved patients who left the Emergency Department AMA. Illness-related factors were the second most frequent reason for 72 hours URVs (34.7\% of total bounce-back reasons). A large proportion of these subjects showed failure to improve (94.1\%) (Table 2 ). In contrast, only one patient returned for treatment side-effects. Doctor-related factors constituted the least common reason for 72 hours URVs (16.3\%). Among the reasons for AMA, personal reasons and unavailability of beds were the most frequent $(33.3 \%)$ followed by overcrowding and leaving the Emergency Department without permission, respectively. In addition, our multivariable analysis revealed that AMA, male sex, and hypertension were the most important independent predictors of 72 hours URVs (Tables 3 and 4). 
Jenab Yet al.

\begin{tabular}{|c|c|c|c|c|}
\hline Variables & Total $(n=245)$ & Cases $(n=49)$ & Controls $(n=196)$ & PValue \\
\hline Male & $123(50.2)$ & $34(69.4)$ & $89(45.4)$ & 0.003 \\
\hline Age, years & $51.86 \pm 17.25$ & $57.12 \pm 15.12$ & $50.54 \pm 17.53$ & 0.010 \\
\hline Dyspnea & $89(36.3)$ & $10(20.4)$ & $79(40.3)$ & 0.010 \\
\hline Systolic blood pressure & $139.89 \pm 23.27$ & $141.50 \pm 23.01$ & $139.55 \pm 23.37$ & 0.606 \\
\hline Heart rate & $78.23 \pm 18.06$ & $76.64 \pm 18.04$ & $78.57 \pm 18.10$ & 0.395 \\
\hline Hypertension & $68(27.8)$ & $22(44.9)$ & $46(23.5)$ & 0.003 \\
\hline Diabetes mellitus & $38(15.5)$ & $14(28.6)$ & $24(12.2)$ & 0.005 \\
\hline Current smoker & $25(10.2)$ & $9(18.4)$ & $16(8.2)$ & 0.035 \\
\hline Dyslipidemia & $40(16.3)$ & $14(28.6)$ & $26(13.3)$ & 0.010 \\
\hline Family history of CAD & $19(7.8)$ & $5(10.2)$ & $14(7.1)$ & 0.549 \\
\hline History of CAD & $38(15.5)$ & $12(24.5)$ & $26(13.3)$ & 0.361 \\
\hline Drug abuse & $5(2)$ & $3(6.1)$ & $2(1.0)$ & 0.056 \\
\hline Abnormal ECG & $90(36.7)$ & $20(40.8)$ & $70(35.7)$ & 0.508 \\
\hline
\end{tabular}

a Abbreviations: CAD, Coronary Artery Disease; ECG, Electro Cardiogram.

$\mathrm{b}$ Data are presented as No. (\%) or mean \pm SD.

\begin{tabular}{|c|c|c|c|c|}
\hline Variables & Total $(n=245)$ & Cases $(n=49)$ & Controls $(n=196)$ & P Value \\
\hline First visit & & & & $<0.001$ \\
\hline Discharged after first visit & $97(39.6)$ & $11(22.4)$ & $86(43.9)$ & \\
\hline Discharged after admission to CPU & $124(50.6)$ & $14(28.6)$ & $110(56.1)$ & \\
\hline AMA from CPU & $24(9.8)$ & $24(49.0)$ & $0(0)$ & \\
\hline \multicolumn{5}{|l|}{ Second visit } \\
\hline Discharged after second visit & & $18(36.8)$ & & \\
\hline Discharged after admission to CPU & & $15(30.6)$ & & \\
\hline Admitted to CCU & & $15(30.6)$ & & \\
\hline AMA from CPU & & $1(2)$ & & \\
\hline
\end{tabular}

a Abbreviations: AMA, Against Medical Advice; CCU, Cardiac Care Unit; CPU, Chest Pain Unit; ED, Emergency Department.

\begin{tabular}{lc}
\hline Table 3. Reasons for 72 Hours Unscheduled Return Visits \\
\hline Variables & Cases $(\mathbf{n}=\mathbf{4 9})$ \\
\hline Illness-related & $17(34.7)$ \\
\hline Failed to improve & $16(94.1)$ \\
\hline Treatment side effects & $1(5.9)$ \\
\hline Patient-related & $24(49)$ \\
\hline Against medical advice & $24(100)$ \\
\hline Doctor-related & $8(16.3)$ \\
\hline Treatment error & $4(50.0)$ \\
\hline Diagnostic error & $4(50.0)$ \\
\hline
\end{tabular}

Table 4. Multivariate Analysis of Factors Associated With 72 Hours Unscheduled Return Visits ${ }^{\text {a }}$

\begin{tabular}{lccc}
\hline Variables & OR & CI (95\%) & P Value \\
\hline Age & 1.03 & $0.995-1.054$ & 0.092 \\
Male Sex & 3.13 & $1.304-8.140$ & 0.010 \\
Hypertension & 3.31 & $1.203-9.489$ & 0.020 \\
$\begin{array}{l}\text { First visit disposition to } \\
\text { ED observation }\end{array}$ & 0.37 & $0.125-1.030$ & 0.057 \\
Against medical advice & 182.36 & $22.186-$ & $<0.001$ \\
& & 23803.34 & \\
\hline
\end{tabular}

a Abbreviation: ED, Emergency Department; OR, Odds Ratio. 


\section{Discussion}

In this retrospective, case-control study, we found that in our CPU, leaving the Emergency Department AMA, male sex, and hypertension were the most important predictors of 72 hours URVs. Also, age was the other associated factor. Equally important, first visit disposition to observation unit had a protective effect on URVs. Emergency Department return visits can lead to overcrowding and longer waiting times and can, thus, exert a negative impact on the quality of health care, time-to-treatment results and treatment outcomes. The 72-hour time point has been defined as a benchmark for measuring the Emergency Department return visits $(16,17)$.

In our study, the return pattern showed that the average age in the case group was seven years older than that of the control group and this difference was significant ( $P$ value $=0.01$. . However, this was not a significant correlation according to the multivariate analysis. Recurrent visits of elderly patients to the Emergency Department are an important component of increased URVs to the Emergency Department. A systematic review of elderly patients at the Emergency Department demonstrated that these patients were more likely to have an Emergency Department return $(1,18)$. Consequently, older patients with chest pain should be evaluated with more caution and should not be discharged unless the source of their problem is defined correctly.

One of other important risk factors for URVs among our study population was the male sex. There were significantly more males in the case group than in the control group. In a similar study at a general Emergency Department, Sauvin et al. (19) demonstrated that $64 \%$ of their revisits were made by men. In contrast, White et al. (17) reported that females slightly outnumbered males among those who made URVs. Nonetheless, some other studies did not find significant differences with respect to URVs between the different sexes $(18,20)$.

Another predictor of 72 hours URVs in our study was a history of hypertension. There were significantly more patients with a history of hypertension in the case group ( $\mathrm{P}$ value $=0.003)$. Hypertension is a major risk factor for coronary artery disease, heart failure, variety of arrhythmias, and sudden death. This finding may also reflect the fact that patients with hypertension are more concerned about their symptoms and are likely to return to the hospital after their first visit.

Among factors associated with URVs in our study, patient-related factors were the most common contributors to URVs. Illness-related and doctor-related factors were determined as the second and third most frequent associated factors. Leaving the hospital AMA was the single cause of patient-related returns to the Emergency Department. Patients who leave AMA probably need further care and, consequently, expose themselves to an increased risk of adverse medical outcomes. In a large retrospective study, patients with Myocardial Infarction (MI) who left AMA had a $40 \%$ higher risk for death and readmission owing to MI during the next two years $(21,22)$. Another study demonstrated that more than one in six AMA patients return to the hospital within 30 days (23). The phenomenon of AMA is worldwide and is not limited to underdeveloped countries. To the best of our knowledge, there is a paucity of data on the medical importance and etiologies of leaving AMA from a CPU. Identification of the risk factors allied with leaving the hospital AMA is the first step in designing strategies to decrease the occurrence of leaving AMA, to prevent a large proportion of URVs, and to boost health care quality. Leaving AMA has a multi-factorial etiology. Given that in our study, the most frequent reasons for leaving AMA were personal reasons and unavailability of beds, it is reasonable to suggest that CPUs should be expanded and more proper strategies be devised in order to prevent URVs. Some of these strategies could include proper counseling and full clear explanation about the potential adverse outcomes of leaving AMA, informing the patient about risks, benefits, and the consequences of such decision. It is also equally important to allow patients sufficient time so that they can properly weigh up their options (24). According to the old adage, words are necessary as drugs in treatment. Therefore, the application of these strategies necessitates good communication skills and good patient-physician relationships (21).

In our study, illness-related factors were the second most frequent reason for all URVs. Ng et al. (22) reported that the most common reason for URVs was illnessrelated, which is similar to the finding in the Wong's study (25). In contrast, Pierce from the USA reported that patient-related factors were the most important cause of bounce backs (24). In our study, with the exception of one case, lack of improvement in the illness was identified as the illness-related factor. Patients with worsened symptoms usually return to the Emergency Department shortly after discharge. Many of these short-time failures and worsening symptoms can be prevented by longer monitoring before discharge $(20,24)$. Furthermore, thorough and comprehensive explanations before discharge in the form of written instructions and pamphlets can prevent some of such URVs.

Doctor-related factors were responsible for only $16.3 \%$ of all studied URVs. In another study, doctor-related issues made up a small minority of the reasons for return (22) An overcrowded Emergency Department creates an overload for treating physicians and therefore, physicians may be blamed for some URVs. Correct diagnosis and management of patients and, by extension, lessening of the risk of untimely discharge from the Emergency Department requires longer monitoring periods and repeated examinations before discharge.

\subsection{Limitations}

This study had some limitations. Firstly, it presents the experience of a teaching hospital with a CPU and these 
findings may, consequently, not be applicable to other CPUs. Secondly, its retrospective design and small sample size limit the extension of the results. Thirdly, we only enrolled patients who presented chest pain and, thus, did not include patients presenting non-chest pain complaints such as shortness of breath, nausea, and other non-specific symptoms. Also, some of URVs occurred at other centers, which we did not investigate. Equally important, in case-control studies, information bias is common, and in our study the main decisions were based on the obtained information.

In the present study, we sought to identify the causes of 72 hours URVs to our CPU with a view to propose preventive strategies. Our results demonstrated that the patients who left the Emergency Department AMA were more likely to return to the Emergency Department. In addition, male sex and history of hypertension were the most important independent predictors of 72 hours URVs.

\section{Authors' Contributions}

Study concept and design, critical revision of the manuscript and study supervision: Yaser Jenab. Analysis and interpretation of data: Arash Jalali. Drafting of the manuscript and abstract: Shima Haghani.

\section{References}

1. Pham JC, Kirsch TD, Hill PM, DeRuggerio K, Hoffmann B. Seventy-two-hour returns may not be a good indicator of safety in the emergency department: a national study. Acad Emerg Med. 2011;18(4):390-7.

2. Nunez S, Hexdall A, Aguirre-Jaime A. Unscheduled returns to the emergency department: an outcome of medical errors? Qual Saf Health Care. 2006;15(2):102-8.

3. Hu SC. Analysis of patient revisits to the emergency department. Am J Emerg Med.1992;10(4):366-70.

4. Hung SC, Chew G, Kong CT, Hsiao CT, Liaw SJ. Unplanned emergency department revisits within 72 hours. J Emergency Med Taiwan. 2004;6(1):230-8.

5. Shalev A, Zahger D. The chest pain unit: doing it right or overdoing it? Isr Med Assoc J. 2010;12(6):377-8.

6. Lee TH, Goldman L. Evaluation of the patient with acute chest pain. NEngl J Med. 2000;342(16):1187-95.

7. Lewis WR, Amsterdam EA. Defining the role of chest pain units $* *$ Editorials published in the Journal of the American College of Cardiology reflect the views of the authors and do not necessarily represent the views of JACC or the American College of Cardiology. J Am Coll Cardiol. 2001;37(8):2050-2.

8. Gershwin ME, Hamilton ME. The Pain Management Handbook: A Concise Guide to Diagnosis and Treatment.: Springer; 1998.

9. Olona M, Candell-Riera J, Permanyer-Miralda G, Castell J, Barrabes JA, Domingo E, et al. Strategies for prognostic assessment of uncomplicated first myocardial infarction: 5-year follow-up study. J Am Coll Cardiol.1995;25(4):815-22.

10. Rowland K, Maitra AK, Richardson DA, Hudson K, Woodhouse KW. The discharge of elderly patients from an accident and emergency department: functional changes and risk of readmission. Age Ageing. 1990;19(6):415-8.

11. Ruccione KS, Waskerwitz M, Buckley J, Perin G, Hammond GD. What caused my child's cancer? Parents' responses to an epidemiology study of childhood cancer. J Pediatr Oncol Nurs. 1994;11(2):71-84.

12. Kelly AM, Chirnside AM, Curry CH. An analysis of unscheduled return visits to an urban emergency department. $N$ Z Med J. 1993;106(961):334-6.

13. Schenkel S. Promoting patient safety and preventing medical error in emergency departments. Acad Emerg Med. 2000;7(11):1204-22.

14. Firth D. Bias reduction of maximum likelihood estimates. Biometrika.1993;80(1):27-38.

15. R core team.. A language and environment for statistical computing. Vienna (Austria): R Foundation for Statistical Computing. 2013. Available from: http:|/www.R-project.org/. Version:http://www.Rproject.org;http://www.R-project.org.

16. Goldman RD, Ong M, Macpherson A. Unscheduled return visits to the pediatric emergency department-one-year experience. Pediatr Emerg Care. 2006;22(8):545-9.

17. White D, Kaplan L, Eddy L. Characteristics of patients who return to the emergency department within 72 hours in one community hospital. Adv Emerg Nurs J. 2011;33(4):344-53.

18. Ross MA, Hemphill RR, Abramson J, Schwab K, Clark C. The recidivism characteristics of an emergency department observation unit. Ann Emerg Med. 2010;56(1):34-41.

19. Sauvin G, Freund Y, Saïdi K, Riou B, Hausfater P, Gaddis G. Correction: Unscheduled Return Visits to the Emergency Department: Consequences for Triage. Acad Emerg Med. 2013;20(3):E3-9.

20. Wu CL, Wang FT, Chiang YC, Chiu YF, Lin TG, Fu LF, et al. Unplanned Emergency Department Revisits within 24 Hours in a Referral Hospital. ROC Emergency Med Care Mag. 2008;19(4):146-54.

21. Al Ayed I. What makes patients leave against medical advice? J Taibah Univ Med Sci. 2009;4(1):16-22.

22. $\mathrm{Ng} \mathrm{CP}$, Chung $\mathrm{CH}$. An analysis of unscheduled return visits to the accident and emergency department of a general public hospital. Hong Kong J Emergency Med. 2003;10(3):153-61.

23. Glasgow JM, Vaughn-Sarrazin M, Kaboli PJ. Leaving against medical advice (AMA): risk of 30-day mortality and hospital readmission. J Gen Intern Med. 2010;25(9):926-9.

24. Pierce JM, Kellerman AL, Oster C. "Bounces": an analysis of shortterm return visits to a public hospital emergency department. Ann Emerg Med. 1990;19(7):752-7.

25. Wong TW, Lam KW. Reattendance audit in an inner-city emergency department. J Accid Emerg Med. 1994;11(4):213-7. 